\title{
Effects of Strain Rate during Multi-Directional Forging on Grain Refinement and Mechanical Properties of AZ80Mg Alloy
}

\author{
H. Miura ${ }^{1, *}$, M. Kobayashi ${ }^{1}$ and T. Benjanarasuth ${ }^{2}$ \\ ${ }^{1}$ Department of Mechanical Engineering, Toyohashi University of Technology, Toyonaka 441-8580, Japan \\ ${ }^{2}$ Faculty of Engineering, King Mongkut's Institute of Technology, Ladkrabang, Bangkok 10520, Thailand
}

\begin{abstract}
Samples of AZ80Mg alloy were multi-directionally forged (MDFed) at various strain rates in the rage from $3.0 \times 10^{-3} \mathrm{~s}^{-1}$ to $3.0 \times 10^{-1} \mathrm{~s}^{-1}$ under decreasing temperature conditions. The MDFing pass temperatures employed were $653 \mathrm{~K}, 605 \mathrm{~K}$ and $553 \mathrm{~K}$. These passes, each of 0.5 strain, were applied up to a cumulative strain of $\Sigma \Delta \varepsilon=1.5$ at maximum. The average grain size decreased with increasing cumulative strain and depended only weakly on the strain rate. Microstructures with average grain sizes of $0.84 \mu \mathrm{m}, 0.88 \mu \mathrm{m}$ and $1.2 \mu \mathrm{m}$ were attained when MDFed at strain rates of $3.0 \times 10^{-1} \mathrm{~s}^{-1}, 3.0 \times 10^{-2} \mathrm{~s}^{-1}$ and $3.0 \times 10^{-3} \mathrm{~s}^{-1}$. The microstructure evolved at $3.0 \times 10^{-1} \mathrm{~s}^{-1}$ was less homogeneous. This difference is interpreted as being due to the higher stored energy causing static recrystallization in the latter MDFing condition. As a result, the best balance of the mechanical properties was attained by MDFing at $3.0 \times 10^{-2} \mathrm{~s}^{-1}$. In this case, ultimate tensile strength (UTS) of $445 \mathrm{MPa}$ was achieved together with a fracture strain of $22 \%$. By comparison, MDFing at $3.0 \times 10^{-1} \mathrm{~s}^{-1}$ led to lower UTS and ductility of $410 \mathrm{MPa}$ and $15 \%$ while the yield stresses were comparable. [doi:10.2320/matertrans.MH201504]
\end{abstract}

(Received February 29, 2016; Accepted March 15, 2016; Published August 25, 2016)

Keywords: AZ80 magnesium alloy, ultrafine grains, multi-directional forging, mechanical properties, recrystallization

\section{Introduction}

Grain refinement is one of the most effective methods of improving the mechanical properties of $\mathrm{Mg}$ and $\mathrm{Mg}$ alloys ${ }^{1-6)}$. When $\mathrm{Mg}$ alloys are fabricated by severe plastic deformation (SPD), notable strengthening is achieved without reducing the ductility. Due to the poor ductility of $\mathrm{Mg}$ alloys, however, these SPD processes are mainly carried out at elevated temperatures. For examples, Kwak et al. ${ }^{4)}$ and Gzyl et al. ${ }^{5)}$ have carried out equal channel angular pressing (ECAP) of $\mathrm{Mg}$ and of $\mathrm{AZ} 31 \mathrm{Mg}$ alloy respectively at elevated temperatures. While they reported improvements in ductility, they did not achieve significant strengthening. This was attributed to the softening associated with their hot ECAP process. Kai et al. subjected a $\mathrm{Mg}-\mathrm{Al}$ alloy to high pressure torsion (HPT) at $298 \mathrm{~K}$ and $423 \mathrm{~K}^{6}$. They produced an ultrafine grained (UFGed) microstructure in this way, which was associated with higher hardness. The HPT at $298 \mathrm{~K}$ was not accomplished to high strain region due to low ductility. SPD of $\mathrm{Mg}$ alloys is, therefore, quite difficult owing to the brittle nature.

Nevertheless, $\mathrm{Mg}$ alloys can be subjected successfully to room-temperature SPD processing if they are either processed under hydrostatic pressure ${ }^{6)}$ or if small pass strains are employed $^{7)}$. An example of the latter approach involves the multi-directional forging (MDFing) under decreasing temperature conditions. In that work, AZ31Mg alloy produced a uniform microstructure with an average grain size of $300 \mathrm{~nm}$. Their product displayed an excellent balance of strength (UTS $=530 \mathrm{MPa}$ ) and ductility $(15 \%)$ by MDFing to a cumulative strain of $\Sigma \Delta \varepsilon=7.2$, i.e., using 9 passes of 0.8 strain per MDFing pass ${ }^{3)}$.

More recently, Miura et al. applied MDFing to AZ61Mg alloy and achieved UTS of $440 \mathrm{MPa}$ at a reduced cumulative strain of $\Sigma \Delta \varepsilon=4.0$. They then increased the strength still further by ageing and cold rolling leading to UTS of $550 \mathrm{MPa}$ with $25 \%$ ductility $^{8}$. By carrying out these operations at ele-

*Corresponding author, E-mail: miura@me.tut.ac.jp vated temperatures, they provoked the occurrence of dynamic recrystallization (DRX), which suppressed the formation and propagation of cracks $^{8,9)}$. The new fine grains also contributed to improving the ductility at ambient temperature.

There are few reports about the effect of SPD strain rate on grain refinement and mechanical properties. Although it is known that DRX can produce finer grain sizes when higher strain rates are used ${ }^{9)}$, the employment of higher strain rates can have additional effects due to the suppression of recovery. In the present study, the MDFing of AZ80Mg alloy was therefore carried out at various strain rates in order to determine the effects of strain rate on the evolved microstructure and mechanical properties.

\section{Experimental}

Hot-extruded AZ80Mg alloy was annealed at $748 \mathrm{~K}$ for $6.3 \mathrm{ks}$ so as to have an initial grain size of $38.4 \mu \mathrm{m}$. It was electro-discharge machined into rectangular samples with dimensions of $32 \times 25 \times 19 \mathrm{~mm}^{3}$ (aspect ratios of 1.7: 1.3: 1). These were MDFed in vacuum on an Instron-type mechanical testing machine at true strain rates of $3.0 \times 10^{-3} \mathrm{~s}^{-1}, 3.0 \times$ $10^{-2} \mathrm{~s}^{-1}$ and $3.0 \times 10^{-1} \mathrm{~s}^{-1}$. The first forging axis was parallel to the extrusion axis. MDFing was carried out using pass strains of $\Delta \varepsilon=0.5$ to cumulative strains of $\Sigma \Delta \varepsilon=1.5$ at maximum. Such cumulative strains are much lower than those employed in previous reports ${ }^{3,8)}$. The pass strains were reduced to $\Delta \varepsilon=0.5$ to avoid the buckling during MDFing at higher strain rates. The temperature of each pass was reduced by $50 \mathrm{~K}$ from $653 \mathrm{~K}$ to $603 \mathrm{~K}$ and then to $553 \mathrm{~K}$. These temperatures were determined by prior experiments to produce homogeneous microstructures without cracking.

The procedure employed is illustrated schematically in Fig. 1. The forging axis was changed by 90 degrees pass by pass. After forging, the samples were water quenched within $10 \mathrm{~s}$ so as to preserve the deformed microstructures as possible. The latter was then examined on the previously forged plane using optical microscopy and transmission electron mi- 
croscopy (TEM). The average grain sizes were measured by the line-intercept method using more than five TEM micrographs. Vickers micro-hardness tests were carried out on the same plane. Finally, tensile samples with gage dimensions of $2.5 \times 5.0 \times 0.7 \mathrm{~mm}^{3}$ were electro-discharge machined so that the tensile direction was perpendicular to the final forging axis of MDFing. These tests were carried out on an Instron-type mechanical testing machine at ambient temperature at an initial strain rate of $1.0 \times 10^{-3} \mathrm{~s}^{-1}$.

\section{Results}

\subsection{MDF flow curves}

Some true stress vs. cumulative strain curves produced during the present MDFing experiments are illustrated in

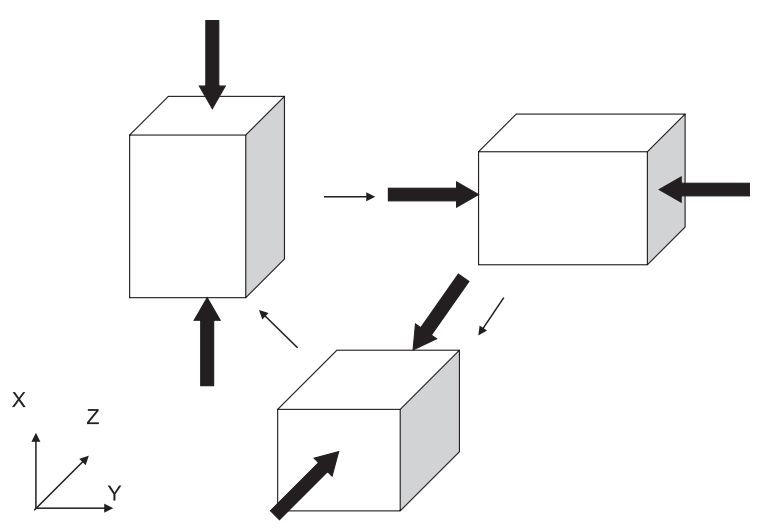

Fig. 1 Schematic illustration of multi-directional forging. Sample is forged with changing forging direction $\mathrm{x} \rightarrow \mathrm{y} \rightarrow \mathrm{z}$ pass by pass. Each pass of forging temperature was decreased from $653 \mathrm{~K}$ to $603 \mathrm{~K}$ and then to $553 \mathrm{~K}$ pass by pass
Fig. 2. The generated flow stress level increased with strain rate and decreasing temperature. The peak stress also increased with increasing strain rate. It is evident that all the peaks are followed by notable work softening. This might be associated with the occurrence of extensive DRX. However, almost constant peak strain independent of deformation condition suggests that softening is mainly affected by some other mechanisms. It is of interest that a steady state of flow was not achieved at the highest strain rate, nor did the microstructure attain a homogeneous state.

The dependence of the peak stress on strain rate is depicted in Fig. 3. The peak stress increased with strain rate. It should be noted that the slope at $10^{-3} \mathrm{~s}^{-1}$ looks quite small even when MDFed at lower temperatures at higher cumulative

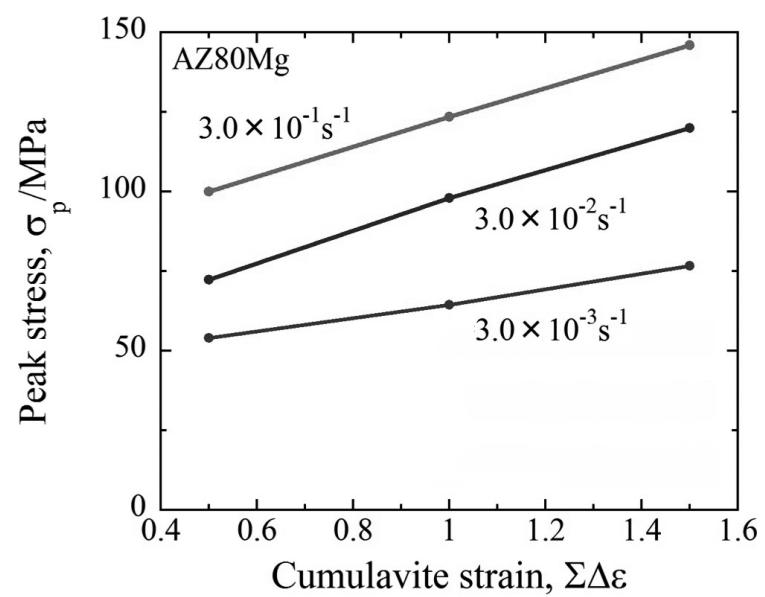

Fig. 3 Dependence of peak stress on cumulative strain and multi-directional forging strain rate. Temperature of each pass of forging was decreased pass by pass form $653 \mathrm{~K}$ down to $553 \mathrm{~K}$ as described in Fig. 2.
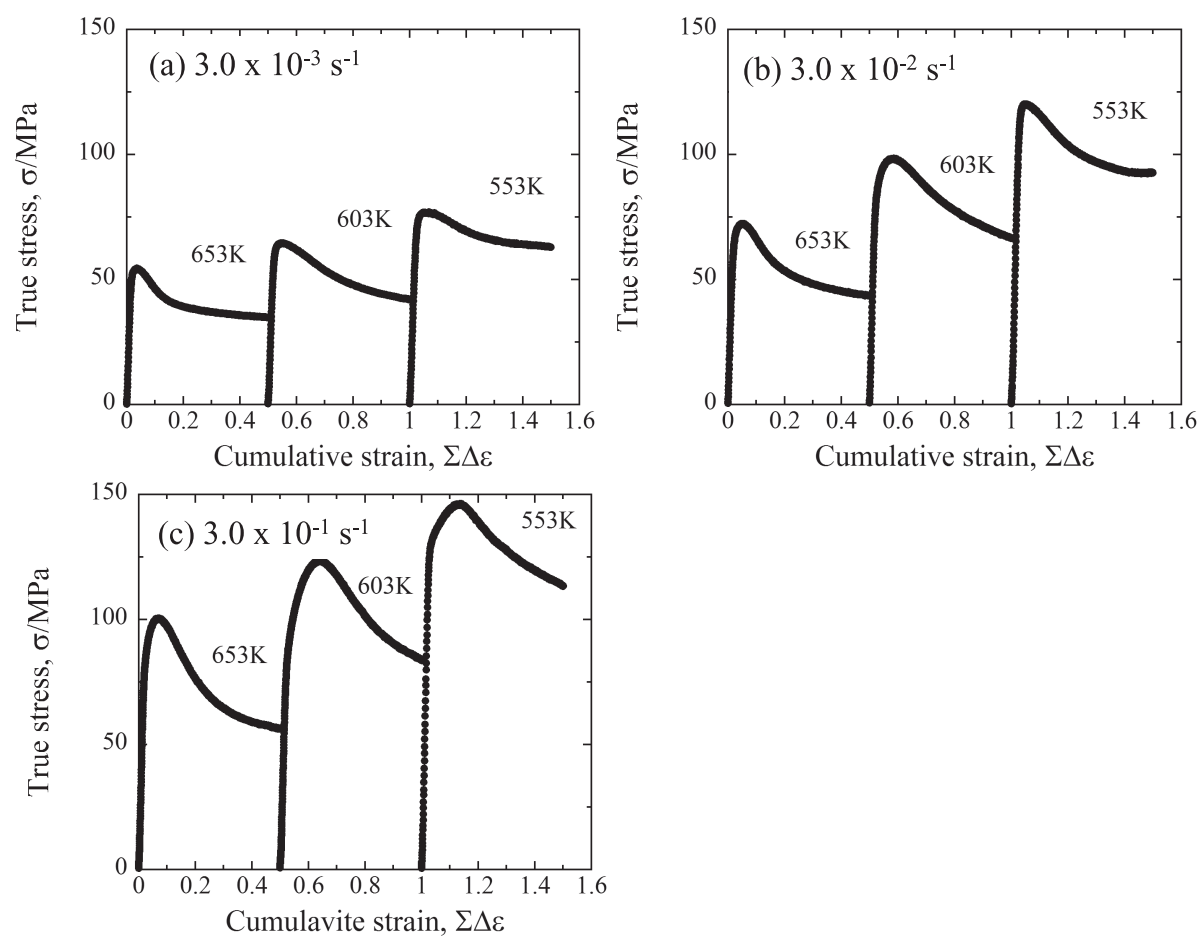

Fig. 2 True stress vs. cumulative strain curves produced by multi-directional forging of $\mathrm{AZ} 80 \mathrm{Mg}^{-}$alloy at various true strain rates of (a) $3.0 \times 10^{-3} \mathrm{~s}^{-1}$, (b) $3.0 \times 10^{-2} \mathrm{~s}^{-1}$, (c) $3.0 \times 10^{-1} \mathrm{~s}^{-1}$. 


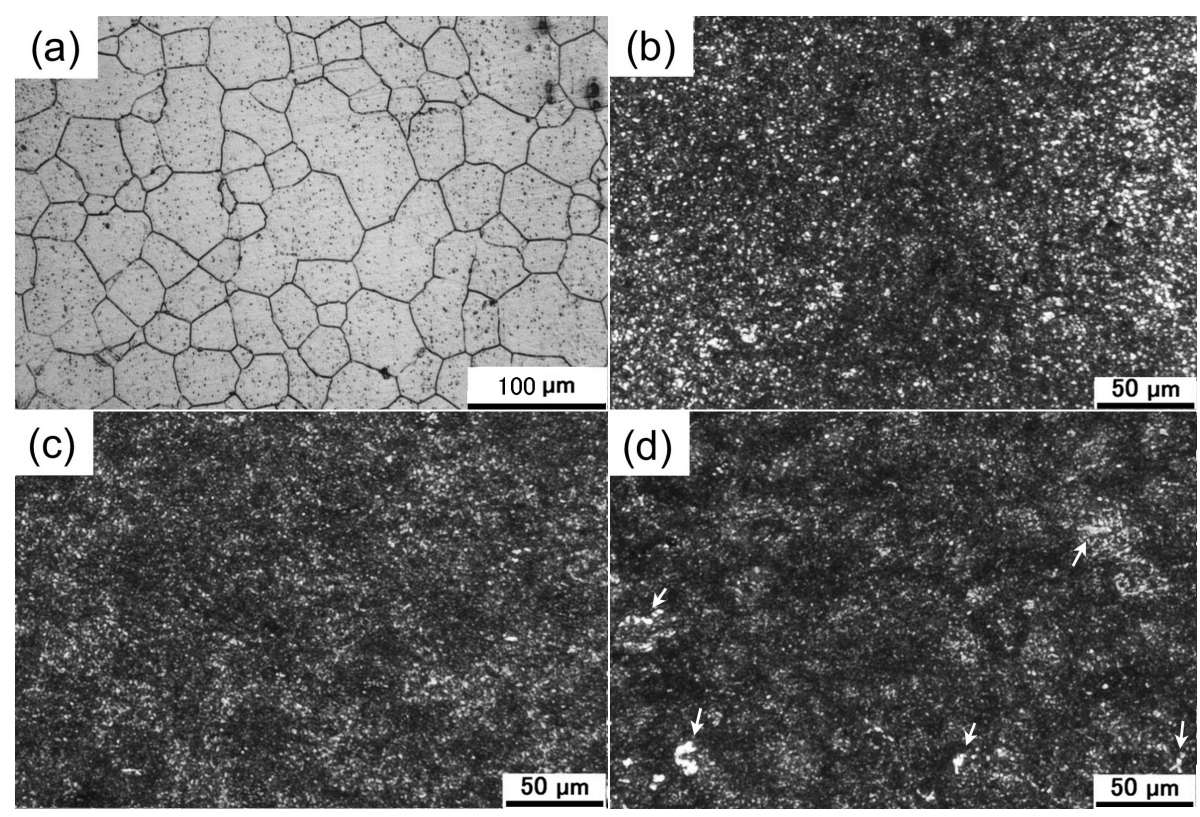

Fig. 4 Optical microstructures of samples (a) before multi-directional forging, and after multi-directional forging to a cumulative strain of $\Sigma \Delta \varepsilon=1.5$ at strain rate of (b) $3.0 \times 10^{-3} \mathrm{~s}^{-1}$, (c) $3.0 \times 10^{-2} \mathrm{~s}^{-1}$, (d) $3.0 \times 10^{-1} \mathrm{~s}^{-1}$. Arrow marks in (d) indicate newly developed coarse grains.

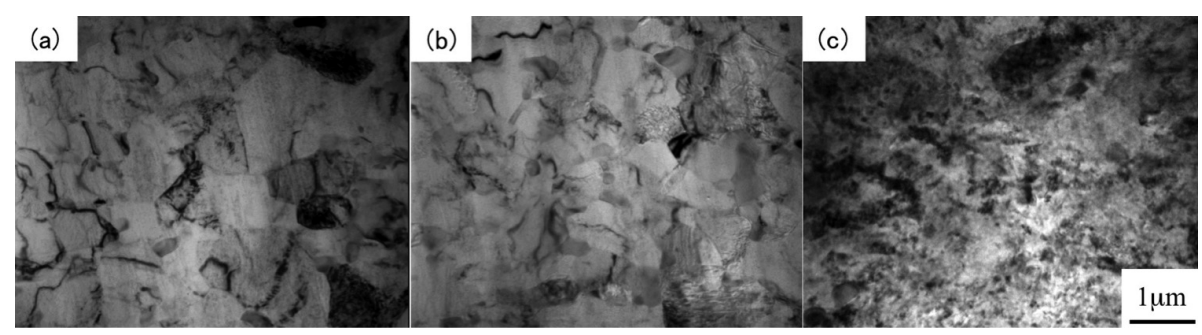

Fig. 5 Evolved microstructures after multi-directional forging to a cumulative strain of $\Sigma \Delta \varepsilon=1.5$ at strain rate of (a) $3.0 \times 10^{-3} \mathrm{~s}^{-1}$, (b) $3.0 \times 10^{-2} \mathrm{~s}^{-1}$, (c) $3.0 \times 10^{-1} \mathrm{~s}^{-1}$.

strain regions. This should be due to evolution of UFGed structure, in which grain-boundary sliding is the most dominant deformation mechanism at elevated temperatures ${ }^{8)}$. Grain-boundary sliding is more sensitive to strain rate than dislocation motion. Therefore, the sliding becomes harder with increasing strain rate.

\subsection{Microstructures produced by MDFing}

Some typical microstructures produced by MDFing to a cumulative strain of $\Sigma \Delta \varepsilon=1.5$ are exhibited in Fig. 4. It can be seen that homogeneous microstructures were developed at all these strain rates. Nevertheless, some coarse grains around $10 \mu \mathrm{m}$ in diameter were present in the samples deformed at $3 \times 10^{-1} \mathrm{~s}^{-1}$ (Fig. 4 (d)). The reasons responsible for their formation will be discussed later.

The MDF microstructures were also examined using TEM; some examples are presented in Fig. 5. It can be seen that the dislocation density in the grain interiors increased with strain rate. The average grain sizes estimated from a large number of micrographs were $0.84 \mu \mathrm{m}, 0.88 \mu \mathrm{m}$ and $1.2 \mu \mathrm{m}$ in samples deformed at the strain rates of $3.0 \times 10^{-1} \mathrm{~s}^{-1}, 3.0 \times$ $10^{-2} \mathrm{~s}^{-1}$ and $3.0 \times 10^{-3} \mathrm{~s}^{-1}$, respectively. Thus, UFGed microstructures were successfully produced at all the strain rates employed in the present study. The summarized changes in

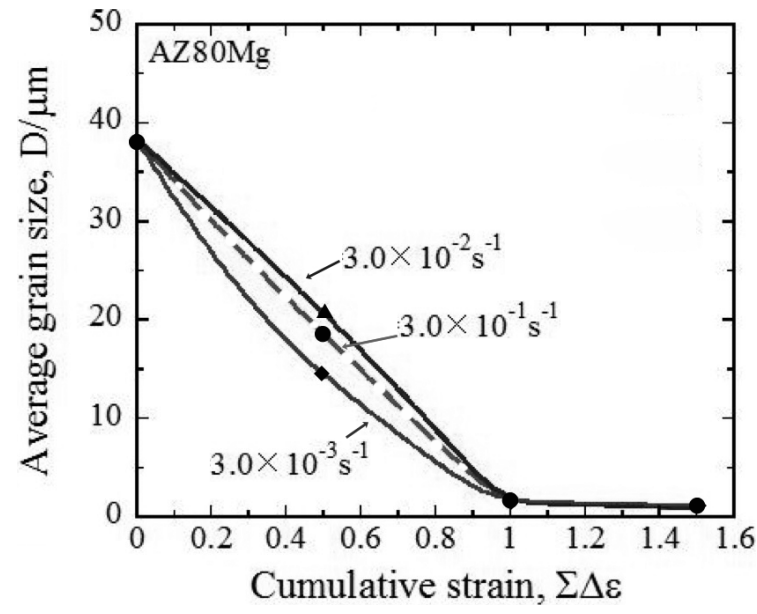

Fig. 6 Dependence of grain size on cumulative strain and strain rate of multi-directional forging.

grain size during MDFing are shown in Fig. 6. Only small differences were observed over the cumulative strain region over $\Sigma \Delta \varepsilon=1.0$. 


\subsection{Mechanical properties}

The dependence of the microhardness on cumulative strain is illustrated in Fig. 7. It is of interest that the hardness is not sensitive to the flow stress variations depicted in Fig. 2. It can also be seen that the hardness approaches the values produced by MDFing to higher cumulative strains ${ }^{3,8}$. The higher proportion of $\beta$ phase present in the AZ80Mg alloy compared with the $\mathrm{AZ31}{ }^{3)}$ and $\mathrm{AZ61}{ }^{8)} \mathrm{Mg}$ alloys may be conducting to the high hardness attained here (Fig. 7).

The MDFed samples were tensile tested at room temperature and some typical flow curves of specimens MDFed to $\Sigma \Delta \varepsilon=1.5$ are displayed in Fig. 8. It is evident that the tensile behavior depends on the MDFing strain rate. The results of



Fig. 7 Change in micro-Vickers hardness depending on cumulative strain and strain rate.
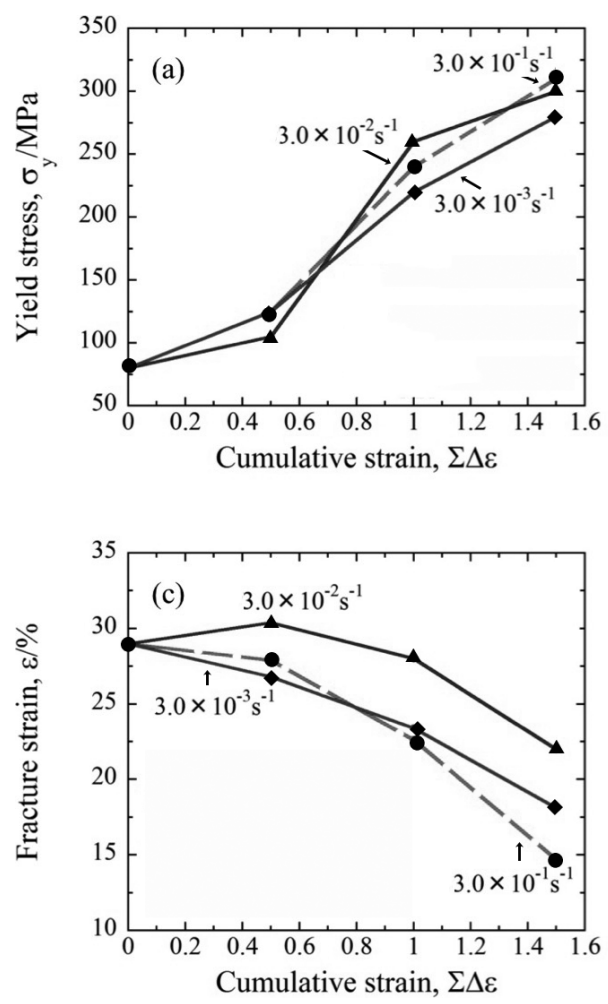

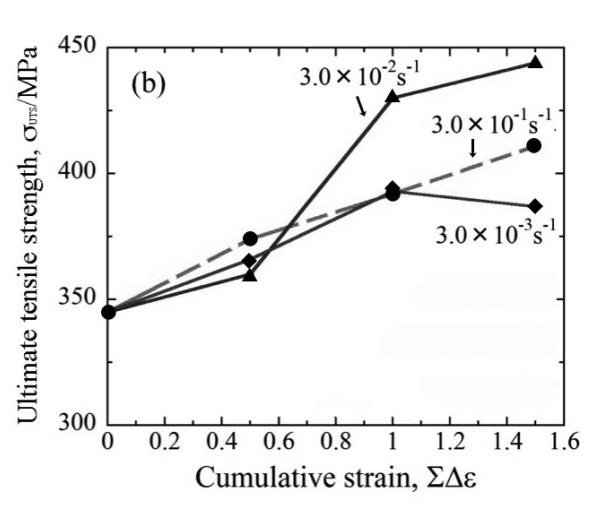

the tensile tests are summarized in Fig. 9. Here it can be seen that MDFing increases the yield stress from $80 \mathrm{MPa}$ to around $300 \mathrm{MPa}$, regardless of the strain rates employed.

\section{Discussion}

The effects of strain rate during MDFing under decreasing temperature conditions of AZ80Mg alloy on grain refinement and mechanical properties were systematically investigated. As shown above, the grain size decreased significantly with increasing cumulative strain and this tendency weakly depended on strain rate. Still more, the mechanical properties

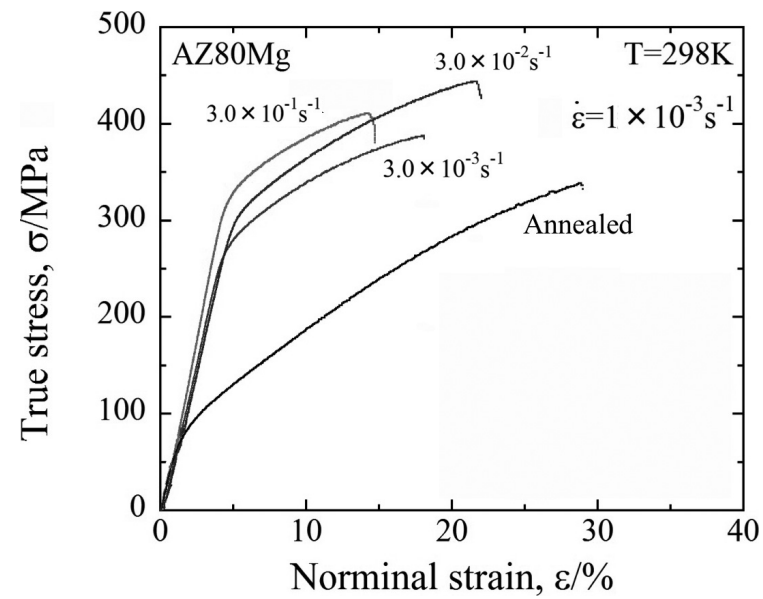

Fig. 8 True stress vs. nominal strain curves obtained by tensile tests of the samples multi-directionally forged to $\Sigma \Delta \varepsilon=1.5$ at the three strain rates. Tensile test was carried out at room temperature and at a strain rate of $1.0 \times 10^{-3} \mathrm{~s}^{-1}$

Fig. 9 Summarized results of tensile tests of (a) yield stress, (b) ultimate tensile strength and (c) fracture strain depending on cumulative strain and multi-directional forging strain rate. Each data point was obtained by one tensile test. 
were also affected by strain rate of MDFing. The factors responsible for these frigid dependencies will be considered more in detail below.

\subsection{MDFing behavior and the evolved microstructure}

Under all conditions, MDFing was successfully carried out to cumulative strains of $\Sigma \Delta \varepsilon=1.5$ without any occurrence of cracking. This can be attributed to the occurrence of extensive DRX. Flow stress changed strongly depended on strain rate (Fig. 2). All the flow curves exhibited particularly sharp peaks followed by appreciable work softening almost irrespective of temperature, strain rate and cumulative strain. Such large work softening during hot deformation is known to appear by extensive occurrence of DRX. DRX behavior is, however, depends strongly on temperature, strain rate and initial grain size $^{9)}$. The peak strain becomes larger with increasing strain rate and grain size and with decreasing temperature when DRX is controlled by thermal activated process by diffusion. The peak strains observed in Fig. 2, however, look almost constant irrespective of forging condition. As already shown, the grain size was reduced with increasing MDFing cumulative strain (Fig. 4). This indicates that the observed flow softening is not diffusion controlled. In other words, the observed work softening in Fig. 2 is not caused mainly by extensive occurrence of conventional DRX.

Yang et al. ${ }^{10)}$ and Miura et al. ${ }^{8,11)}$ precisely investigated the mechanisms of work softening during hot deformation of $\mathrm{Mg}$ alloys. They also reported almost constant peak strains irrespective of experimental conditions and attributed the work softening mainly to geometrical softening by crystal rotation and partially to buckling including twinning and kinking. They have also investigated the effect of texture to work softening and revealed that the work softening is more significant when deformed either parallel or normal to c-axis of the textured $\mathrm{Mg}$ alloys. In such conditions, relatively higher stress is necessary to apply to activate basal and prismatic planes for the plastic deformation. However, lower stress is necessary to activate slip planes after crystal rotation. That is, work softening is affected strongly by the changes of texture and crystallographical geometry. In fact, Kim et al. reported absence of peak strain when basal textured $\mathrm{Mg}$ alloy was hot deformed to the direction 45 degrees $^{12}$. After forging to higher strain region at each forging pass (Fig. 2), the coarser grains were fragmented gradually to form finer microstructure by combined mechanisms of DRX, twinning and kinking ${ }^{8,11)}$. It is also interesting to see in Fig. 2 that the amount of work softening becomes smaller with increasing cumulative strain. Uematsu et al. have precisely investigated change in texture with decreasing grain size of AZ61Mg alloy prepared by MDFing and have revealed that texture becomes less significant with deceasing grain size ${ }^{13)}$. Their observation also semi-qualitatively supports the work softening observed because weaker texture can induce less work softening.

The flow stress increased with increasing cumulative strain and strain rate. The steady-state flow became more difficult to appear with increasing strain rate. This mechanical behavior is completely the same with those of the other metallic materials $^{9)}$. Although steady state-flow was not achieved at some conditions in Fig. 2, almost homogeneous microstructure was obtained at each forging pass.
Grain size was gradually reduced with increasing cumulative strain during MDFing irrespective of strain rate. Almost homogeneous UFGed structures with average grain size of $0.84 \mu \mathrm{m}, 0.88 \mu \mathrm{m}$ and $1.2 \mu \mathrm{m}$, measured by TEM, were achieved by MDFing to a cumulative strain of $\Sigma \Delta \varepsilon=1.5$ at strain rate of $3.0 \times 10^{-1} \mathrm{~s}^{-1}, 3.0 \times 10^{-2} \mathrm{~s}^{-1}$ and $3.0 \times 10^{-3} \mathrm{~s}^{-1}$, respectively. Therefore, the average grain size decreased with increasing strain rate. This tendency, where grain size reduced with increasing strain rate, is in good agreement with expectations based on theory of $\mathrm{DRX}^{9)}$.

However, the microstructure evolved by MDFing at $3.0 \times$ $10^{-1} \mathrm{~s}^{-1}$ looks macroscopically inhomogeneous involving rather coarser grains up to $10 \mu \mathrm{m}$ in diameter. The coarser grains observed in Fig. 4 (d) would be probably formed during re-heating up to following MDFing temperature and during cooling procedure after MDFing. Because of high dislocation density and high strain energy should promote local static recrystallization and, therefore, grain coarsening.

Static recrystallization is significantly stimulated with decreasing grain size ${ }^{14)}$. Furthermore, temperature to onset static recrystallization is drastically lowered by UFG evolution by MDFing ${ }^{15)}$. Actually, it is reported that UFGed AZ61Mg alloy produced by MDFing statically recrystallized and grain coarsening took place even at $423 \mathrm{~K}$ where much lower temperature than the present MDFing conditions ${ }^{16)}$. These coarser grains newly formed during MDFing process and, therefore, microstructural inhomogeneity must affect to the mechanical properties.

The achieved grain size around $1 \mu \mathrm{m}$ with employing rather small pass strains of $\Delta \varepsilon=0.5$ and cumulative strain of $\Sigma \Delta \varepsilon=1.5$ in the present study is almost comparable with the average grain size of $1.2 \mu \mathrm{m}$ achieved in AZ61Mg alloy MDFed to $\Sigma \Delta \varepsilon=3.2$ with employing pass strains of $\Delta \varepsilon=$ $0.8^{8)}$. This would be affected by lower stacking fault energy in $\mathrm{AZ80Mg}$ alloy than in AZ61Mg alloy ${ }^{17)}$ to induce higher density of mechanical twins which contributes to grain refinement at lower strains ${ }^{8)}$.

\subsection{Mechanical properties of the AZ80Mg alloys MDFed at various strain rates}

Almost constant hardness over $930 \mathrm{MPa}$ and yield stress around $300 \mathrm{MPa}$ irrespective of MDFing strain rate were attained after MDFing to cumulative strain of $\Sigma \Delta \varepsilon=1.5$ (Figs. 7, 8, 9). Change in the yield stress was plotted as a function of grain size in Fig. 10. It can be seen in Fig. 10 that all the data can be roughly plotted in straight lines and the difference in the slopes, around 0.004 , looks quite small. This indicates that effect of strain rate on the yield stress is negligibly small. UTS, however, differed much depending on strain rate (Fig. 9 (b)). UTS when MDFed at $3.0 \times 10^{-2} \mathrm{~s}^{-1}$ was highest; $445 \mathrm{MPa}$, while those MDFed at $3.0 \times 10^{-1} \mathrm{~s}^{-1}$ and $3.0 \times 10^{-3} \mathrm{~s}^{-1}$ were lower; $410 \mathrm{MPa}$ and $382 \mathrm{MPa}$, respectively. It is assumed that this difference must be affected by ductility. That is, even while yield stress is comparable, UTS becomes higher when ductility is higher due to larger work hardening region (see Figs. 8, 9 (c)). The reason why the lowest ductility of the sample MDFed at $3.0 \times 10^{-1} \mathrm{~s}^{-1}$ should be owing to the inhomogeneity of microstructure caused by static recrystallization and grain coarsening during MDFing processes (Fig. 4). It is known that inhomogeneity 


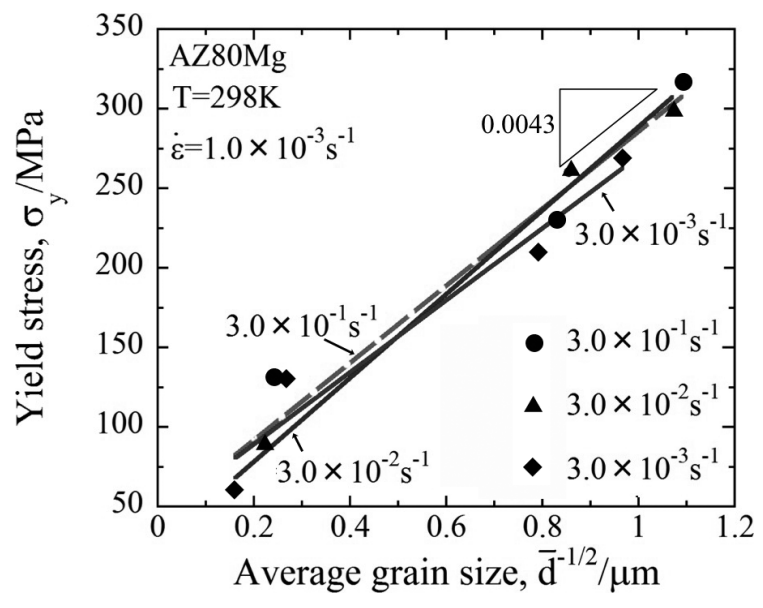

Fig. 10 Hall-Petch plot of the yield stress obtained by tensile tests at room temperature of the AZ80Mg alloy multi-directionally forged at various strain rates.

of microstructure leads to deformation inhomogeneity to induce strain localization and, therefore, loss of ductility ${ }^{18)}$. The inhomogeneous microstructure in the sample MDFed at 3.0 $\times$ $10^{-1} \mathrm{~s}^{-1}$, therefore, derived lowest ductility. Then, the sample MDFed at $3.0 \times 10^{-2} \mathrm{~s}^{-1}$ exhibited largest ductility and, therefore, highest UTS because of the homogeneous evolution of UFGs.

Miura et al. have reported that hardness of $990 \mathrm{MPa}$ was achieved by MDFing of AZ61Mg alloy under decreasing temperature conditions to $\Sigma \Delta \varepsilon=4.0$ where the average grain size $\bar{d}$ was $0.8 \mu \mathrm{m}^{8}$. Xing et al. have also reported high hardness of $1.05 \mathrm{GPa}$ by MDFing of AZ31Mg alloy to $\Sigma \Delta \varepsilon=4.8$ where $\bar{d}=0.36 \mu \mathrm{m}^{3)}$. In the present study, however, almost comparable hardness of $977 \mathrm{MPa}$ could be attained only at $\Sigma \Delta \varepsilon=1.5$.

The MDFed AZ61Mg alloy to $\Sigma \Delta \varepsilon=4.0$ exhibited high yield stress of $300 \mathrm{MPa}$ and UTS of $430 \mathrm{MPa}^{8)}$. Xing et al. reported that superior balance of UFGed AZ31Mg alloy which possessed yield stress of $420 \mathrm{MPa}$, UTS of $520 \mathrm{MPa}$ and plastic strain to fracture of $10 \%$ after MDFing to $\Sigma \Delta \varepsilon=$ 6.4. The results obtained in the present study, i.e., $300 \mathrm{MPa}$ yield stress and $445 \mathrm{MPa}$ UTS, are also again comparable to those of AZ61Mg alloy but lower than those of AZ31 one. However, it should be noted that the applied MDFing cumulative strain was only $\Sigma \Delta \varepsilon=1.5$ in the present study. The rather good mechanical properties could be achieved by UFG evolution by MDFing of AZ80Mg alloy at higher strain rate when compared with the other MDFing conditions ${ }^{3,8)}$. These superior properties may be affected also by high fraction of fine $\beta$ phase particles dispersed in AZ80Mg alloy. Finally, it is concluded that MDFing at suitable strain rate employing DRX can induce more preferable mechanical properties.

\section{Summary}

AZ80Mg alloy was successfully multi-directionally forged (MDFed) under decreasing temperature conditions at various strain rates. The average grain size decreased gradually with increasing cumulative strain and almost homogeneous ultrafine grained (UFGed) structure could be attained only at a cu- mulative strain of $\Sigma \Delta \varepsilon=1.5$. The average grain size achieved at $\Sigma \Delta \varepsilon=1.5$ was $0.84 \mu \mathrm{m}, 0.88 \mu \mathrm{m}$ and $1.2 \mu \mathrm{m}$ at strain rate of $3.0 \times 10^{-1} \mathrm{~s}^{-1}, 3.0 \times 10^{-2} \mathrm{~s}^{-1}$ and $3.0 \times 10^{-3} \mathrm{~s}^{-1}$, respectively. However, less homogeneous microstructure, which was caused by grain coarsening during re-heating for the next MDFing pass and cooling process after MDFing, was developed when MDFed at $3.0 \times 10^{-1} \mathrm{~s}^{-1}$. Even while the yield stress and hardness were almost the same independent of strain rate, ultimate tensile strength and ductility were sensitively changed depending on MDFing strain rate. Therefore, employment of an adequate strain rate for MDFing is necessary to fabricate UFGed structure with superior balance of mechanical properties. The best balance of mechanical properties, i.e., hardness $977 \mathrm{MPa}$, yield stress $300 \mathrm{MPa}$, ultimate tensile strength $445 \mathrm{MPa}$ and ductility $22 \%$, was attained when MDFed at $3.0 \times 10^{-2} \mathrm{~s}^{-1}$.

\section{Acknowledgements}

This research was financially supported by Japan Science and Technology Agency (JST) under Industry-Academia Collaborative R\&D Program "Heterogeneous Structure Control: Towards Innovative Development of Metallic Structural Materials", Grant-in-Aid for Scientific Research on Innovative Areas "Bulk Nanostructured Metals" through MEXT, Japan, Grant No. 22102004, 24360303 and the Light Metals Educational Foundation, Japan. One of the authors, H.M. appreciates discussion with Prof. J.J. Jonas, McGill University and assistance by Mr. R. Watanabe, UEC Tokyo.

\section{REFERENCES}

1) Nanomaterials by severe plastic deformation, ed by Z. Horita, (2005), Trans Tech Publications.

2) N. Tsuji, Y. Ito, Y. Saito and Y. Minamino: Scr. Mater. 47 (2002) 893899.

3) J. Xing, X. Yang, H. Miura and T. Sakai: Trans. JIM 46 (2005) 16461650 .

4) E.J. Kwak, C.H. Bok, M.H. Seo, T.S. Kim and H.S. Kim: Trans. JIM 49 (2008) 1006-1010.

5) M. Gzyl, A. Rosochwski, R. Pesci, L. Olejnik, E. Yakushina and P. Wood: Metall. Mater. Trans., A Phys. Metall. Mater. Sci. 45 (2014) 1609-1620.

6) M. Kai, Z. Horita and T.G. Langdon: Mater. Sci. Eng. A 488 (2008) $117-124$.

7) H. Miura and W. Nakamura: Philos. Mag. Lett. 93 (2013) 601-607.

8) H. Miura, G. Yu and X. Yang: Mater. Sci. Eng. A 528 (2011) 69816992.

9) T. Sakai and J.J. Jonas: Acta Metall. 32 (1984) 189-209.

10) X. Yang, Z.S. Ji, H. Miura and T. Sakai: Trans. Nonferros Met. Soc. China 19 (2009) 55-60.

11) H. Miura, M. Ito, X. Yang and J.J. Jonas: Mater. Sci. Eng. A 538 (2012) 63-68.

12) J. Kim, K. Okayasu and H. Fukutomi: Trans. JIM 53 (2012) 18701875 .

13) Y. Uematsu, T. Kakiuchi, H. Miura, T. Nozaki: submitting to Mater. Trans. (2016).

14) W.B. Hutchinson, S. Jonsson and L. Ryde: Scr. Metall. Mater. 23 (1989) 671-676.

15) Y. Nakao, H. Miura and T. Sakai: Mater. Sci. Forum 558-559 (2007) 1329-1334.

16) H. Miura, G. Yu and X. Yang: Mater. Sci. Eng. A 528 (2011) 69816992.

17) K. Higashi: J. Jpn. Inst. Light Metals 59 (2009) 576-588.

18) F.P.E. Dunne: Int. J. Plast. 14 (1998) 413-433. 